\title{
Osteocalcin-expressing endothelial progenitor cells and serum osteocalcin forms are independent biomarkers of coronary atherosclerotic disease severity in male and female patients
}

\author{
H. E. Shahrour ${ }^{1}$ - S. Al Fahom ${ }^{1}$ - G. Al-Massarani ${ }^{2}$ A. R. AlSaadi ${ }^{3} \cdot$ P. Magni $^{4,5,6}$ (])
}

Received: 25 October 2021 / Accepted: 14 January 2022 / Published online: 28 January 2022

(c) The Author(s) 2022

\begin{abstract}
Purpose Osteocalcin (OC), an osteoblast-derived regulator of metabolic processes, and circulating early endothelial progenitor cells $(\mathrm{EPC}, \mathrm{CD} 34-/ \mathrm{CD} 133+/ \mathrm{KDR}+)$ expressing $\mathrm{OC}(\mathrm{OC}+)$ are potential candidates linking bone metabolism and the vasculature and might be involved in vascular atherosclerotic calcification. This study aimed at assessing the association of circulating levels of different OC forms and of EPCs count with disease severity in patients with documented coronary atherosclerosis (CAD).

Methods Patients $(n=59)$ undergoing coronary angiography were divided, according to stenosis severity, into (1) early coronary atherosclerosis (ECA) $(n=22)$, and (2) late coronary atherosclerosis (LCA) $(n=37)$. Total OC (TOC), carboxylated OC (cOC), undercarboxylated OC (unOC) were quantified by ELISA. EPC OC + count was assessed by flow cytometry.

Results EPC OC + counts showed significant differences between ECA and LCA groups. unOC and unOC/TOC ratio were inversely correlated with EPC OC + count. A significant decrease in TOC and unOC plasma levels was associated with higher cardiovascular risk factors (CVRFs) number. EPC OC + count was correlated with LDL-C, total cholesterol, and triglycerides, with a greater significance in the LCA group. No association between the different forms of circulating OC (TOC, ucOC, cOC) and severity of CAD was found.

Conclusion This study showed a significant association between EPCs (CD34-/CD133 +/KDR +/OC +), CAD severity and CVRFs, suggesting an active role for EPC OC + in the development of CAD. An inverse correlation between TOC, ucOC, and number of CVRFs was observed, suggesting that OC, regardless of its carboxylation status, may be developed as a further cardiovascular risk biomarker.
\end{abstract}

Keywords Coronary atherosclerotic disease - Endothelial progenitor cells · Osteocalcin - Undercarboxylated osteocalcin · Carboxylated osteocalcin $\cdot$ Cardiovascular risk factors

P. Magni

paolo.magni@unimi.it

1 Department of Biochemistry and Microbiology, Faculty of Pharmacy, Damascus University, Damascus, Syria

2 Department Radiation Medicine, Pharmacological Studies Division, Atomic Energy Commission of Syria (AECS), Damascus, Syria

3 Department of Internal Medicine, Cardiovascular Disease Section, Faculty of Medicine, Damascus University, Damascus, Syria

4 Dipartimento di Scienze Farmacologiche e Biomolecolari, Università Degli Studi di Milano, Milan, Italy

5 IRCCS MultiMedica, Sesto S. Giovanni, Milan, Italy

6 DISFeB-UNIMI, via Balzaretti 9, 20133 Milan, Italy

\section{Introduction}

Atherosclerosis is associated with different risk factors, leads to vascular injury and, in conjunction with thrombosis, is the common cause of coronary artery disease (CAD). Although several studies have identified multiple risk factors, associated with the clinical manifestation of the disease $[1,2]$, such as elevated LDL cholesterol (LDL-C) levels, as well as pro-inflammatory components [3], it has not yet been proven that the successful management of these factors, alone or in combination, can completely eliminate or slow down the development of the disease, leading to the concept of cardiovascular $(\mathrm{CV})$ residual risk. The knowledge and validation of additional novel risk factors and reliable predictive biomarkers to be added and integrated with those 
already established is thus urgently required to improve the accuracy of prevention and management of atherosclerosisrelated cardiovascular disease (ASCVD).

Vascular calcification, a major manifestation of atherosclerosis, has long been assumed to result from passive precipitation of calcium and phosphate, but it is now considered to be an active cell-mediated process that results in organized extracellular matrix deposition by osteoblastlike cells [4]. Interestingly, there is an increasing evidence for the involvement of the skeleton in the pathophysiology of ASCVD [5]. The skeleton has indeed been recognized as an endocrine organ [6-9] involved in several metabolic processes, including maintaining normal levels of blood glucose and lipids $[10,11]$. Recent studies identified an additional biological function of osteoblasts, that is focused on the actions of osteocalcin (OC) $[12,13]$. OC is a vitamin $\mathrm{K}$-dependent, osteoblast-derived protein, which exists in the circulation in two forms, carboxylated (cOC) and undercarboxylated (ucOC) [14-16]. Through the secretion of OC, the bone regulates glucose homeostasis $[8,13]$ and male reproductive functions [17, 18]. In addition, clinical studies suggest a more complex role for OC in human metabolism, which led to investigations exploring its associations with CV disease (CVD) [19-22], and to clarify whether OC is a vital mediator or a nonparticipant bystander in energy metabolism and vascular function [23-25]. Another candidate potentially providing a link between bone metabolism and CVD are endothelial progenitor cells (EPCs), which are nucleated bone marrow-derived cells, that can be mobilized in response to vascular injury, and contribute to vascular repair [26, 27]. Interestingly, OC expression by EPCs has an osteogenic potential and might be involved in the modulation of vascular atherosclerotic calcification [5]. Several studies, that examined OC-positive endothelial progenitor cells (EPCs) or performed histological staining for OC, reported that higher OC levels were associated with an increase of markers of atherosclerosis and calcification [28, 29], possibly indicating that these OC-positive EPCs are a promising biomarker for severity stratification of CAD [30].

Based on these findings, the present study was conducted to examine the relationship between the circulating level of the different $\mathrm{OC}$ forms and the count of circulating EPCs $(\mathrm{CD} 34-/ \mathrm{CD} 133+/ \mathrm{KDR}+)$ expressing $\mathrm{OC}(\mathrm{OC}+)$ in a cohort of patients with documented coronary artery atherosclerosis of variable severity.

\section{Methods}

\section{Study cohort}

A cross-sectional study was conducted in a cohort of consecutive patients with coronary artery atherosclerosis. Patients were hospitalized at the cardiac catheterization department in Alassad University hospital (Damascus, Syria). Clinical and demographic data were used in accordance with hospital regulations and patient permission. The occurrence of hard physical work and/or sports practice were used as indicators of physical activity. Patients with impaired renal function, paralysis, debility, stay in bed for more than two weeks, previous hormonal or metabolic disorders, or taking medications known to influence bone or calcium metabolism, such as vitamin $\mathrm{D}$, bisphosphonates, calcitonin, estrogen, corticosteroids, or warfarin, were excluded. This study was conducted in 59 patients (men $61 \%$, women $39 \%$ ) divided into two groups: (1) early coronary atherosclerosis (ECA), 22 patients (men $50 \%$, women $50 \%$ ), aged $55.2 \pm 9.7$ years, defined as patients with mild CAD $(<50 \%$ stenosis in any major epicardial arteries), and (2) late coronary atherosclerosis (LCA), 37 patients (men 68\%, women 32\%), aged $60.6 \pm 10.4$ years, defined as patients with severe, mono/ multivessel CAD ( $>50 \%$ stenosis in at least one or more major epicardial arteries).

Patient were grouped according to having one or more of the following cardiovascular risk factors (CVRFs): (1) history of hypertension: systolic blood pressure $\geqq 140 \mathrm{mmHg}$, diastolic blood pressure $\geqq 90 \mathrm{mmHg}$; (2) history of type 2 diabetes mellitus (T2DM): hemoglobin A1c $\geqq 6.5 \%$, fasting plasma glucose (FPG) $\geqq 126 \mathrm{mg} / \mathrm{dL}$; (3) history of hypercholesterolaemia: total cholesterol (TC) $\geqq 200 \mathrm{mg} / \mathrm{dL}$, LDL-C $\geqq 100 \mathrm{mg} / \mathrm{dL}$; (4) previous/current smoking; (5) obesity, body mass index $\geqq 30 \mathrm{~kg} / \mathrm{m}^{2}$; and (6) family history of premature CAD: CAD in first-degree relatives $<55$ years (male) or $<65$ years (female). Concomitant medications are summarized in Supplemental Table 1. The study was approved by the Human Research Ethics Committee, Faculty of Pharmacy, Damascus University (HRECPHARMDU); all participating subjects signed an informed consent.

\section{Measurement of circulating biomarkers and serum OC forms}

In each blood sample, TC, HDL-C, triglyceride (TG) and FPG were measured according to standard automated clinical procedure. LDL-C was calculated according to the Friedewald formula. The serum levels of different $\mathrm{OC}$ forms in peripheral blood specimen were measured using ELISA testing. Specifically, we measured the serum concentration of ucOC (Glu-OC MK118, Takara Bio Europe SAS, France), cOC (Gla-OC MK111, Takara Bio Europe SAS, France), and TOC (hOST-ELISA KAP1381, DIAsource ImmunoAssays SA, Belgium). Since ucOC levels are affected by bone formation, the ucOC/TOC ratio was calculated to adjust for this effect. Normal range reference values for OC forms, obtained from 26 healthy subjects (38.6 \pm 7.7 years), were: cOC: $7.29 \pm 3.27 \mathrm{mg} / \mathrm{mL}$; ucOC: $6.65 \pm 1.78 \mathrm{mg} / \mathrm{mL}$. 


\section{Evaluation of circulating EPCs OC+}

Flow cytometry was used to count circulating EPCs that were $\mathrm{CD} 34-\mathrm{CD} 133+\mathrm{KDR}+\mathrm{OC}+$. Three $\mathrm{mL}$ of peripheral blood was withdrawn into vacuum tubes containing EDTA as anticoagulant. Blood samples $(200 \mu \mathrm{L})$ were stained with mouse anti-human monoclonal antibodies conjugated with fluorochromes: Anti-OC-APC (R\&D Systems), Anti-CD34-PerCP-Cy5.5 (BD Biosciences), Anti-CD133PE (Miltenyi Biotec), and Anti-KDR-FITC (Miltenyi Biotec). Erythrocytes were then lysed and leukocytes were washed with PBS and resuspended in $950 \mu \mathrm{L}$ PBS. After the addition of $50 \mu \mathrm{L}$ of counting beads, the samples were analyzed using a flow cytometer (MACSQuant ${ }^{\circledR}$, Miltenyi Biotec $\mathrm{GmbH}$ ). Autofluorescence and isotype controls were also included. MACSQuant software was used to acquire and analyze flow cytometric data. A total of 100,000 events in the mononuclear gate were acquired. Counting beads were used to calculate the absolute count of EPCs that were $\mathrm{CD} 34-\mathrm{CD} 133+\mathrm{KDR}+\mathrm{OC}+$, after applying the appropriate gating.

\section{Statistical analysis}

Data was analyzed using the Statistical Package for the Social Sciences v22 (SPSS, Inc., Chicago, Illinois). The Kolmogorov-Smirnov test was performed to assess the sample cumulative distribution. Quantitative continuous variables are presented as mean \pm SD or median and interquartile range. Normally distributed variables were analyzed using the two independent samples $t$-test. To analyze non-normally distributed data, the Mann-Whitney $U$ test was performed. Kruskal-Wallis test was used to compare the mean ranks of TOC, ucOC, and $\mathrm{cOC}$ in relation to the number of cardiovascular risk factors (CVRFs). Spearman correlation coefficient was used to assess the strength of the association among EPC, OC, and CVRFs. Statistical significance was set at $p<0.05$.

\section{Results}

\section{Characteristics of the study cohort}

The demographic, clinical, and biochemical characteristics of the study subjects are shown in Table 1. Patients with LCA were older than ECA subjects $(60.57 \pm 10.42$ vs. $55.23 \pm 9.65$ years, $p=0.013$ ). The $\mathrm{M} / \mathrm{F}$ ratio was $50: 50 \%$ in the ECA group, but males were prevalent (68\%) in the LCA group. LCA and ECA groups did not differ according to incidence of smoking, TC, HDL-C, LDL-C and TG. Patients with T2DM were significantly more in the LCA group than in the ECA group $(p=0.01)$. There were no significant
Table 1 Demographic, anthropometric, and biochemical parameters of the study population

\begin{tabular}{llll}
\hline & ECA $(n=22)$ & LCA $(n=37)$ & $p$ value \\
\hline Age $(\mathrm{yr})$ & $55.23 \pm 9.65$ & $60.57 \pm 10.42$ & $\mathbf{0 . 0 1 3}$ \\
Gender $(\mathrm{M} / \mathrm{F})$ & $11 / 11$ & $25 / 12$ & 0.19 \\
Sedentary lifestyle & $16(72.7)$ & $30(81.1)$ & 0.45 \\
$n(\%)$ & & & \\
Smoking & $7(31.8)$ & $11(29.7)$ & 0.87 \\
$n(\%)$ & & & \\
BMI $\left(\mathrm{kg} / \mathrm{m}^{2}\right)$ & $30.45 \pm 4.85$ & $29.32 \pm 4.43$ & 0.44 \\
SBP $(\mathrm{mmHg})$ & $128.6 \pm 14.9$ & $126.5 \pm 7.5$ & 0.61 \\
DBP $(\mathrm{mmHg})$ & $70.5 \pm 12.1$ & $68.9 \pm 9.9$ & 0.70 \\
TC $(\mathrm{mg} / \mathrm{dL})$ & $156.50 \pm 41.24$ & $149.46 \pm 44.99$ & 0.51 \\
HDL-C (mg/dL) & $31.91 \pm 8.86$ & $27.95 \pm 5.89$ & 0.11 \\
LDL-C (mg/dL) & $88.45 \pm 25.46$ & $83.43 \pm 28.44$ & 0.71 \\
TG $(\mathrm{mg} / \mathrm{dL})$ & $159.36 \pm 78.91$ & $146.59 \pm 85.36$ & 0.17 \\
FPG $(\mathrm{mg} / \mathrm{dL})$ & $160.46 \pm 91.08$ & $166.81 \pm 84.11$ & 0.48 \\
Non-T2DM & $13(59.1)$ & $14(37.8)$ & 0.85 \\
$n(\%)$ & & & \\
T2DM & $9(40.9)$ & $23(62.2)$ & $\mathbf{0 . 0 1}$ \\
$n(\%)$ & & & \\
\hline
\end{tabular}

Data are expressed as mean \pm standard deviation. Significant $p$ values are in bold

$E C A$ early cardiovascular atherosclerosis; $L C A$ late cardiovascular atherosclerosis; $M / F$ male/female; $B M I$ body mass index; $S B P$ systolic blood pressure; $D B P$ diastolic blood pressure; $T C$ total cholesterol; $H D L-C$ cholesterol bound to high density lipoproteins; $L D L-C$ cholesterol bound to low-density lipoproteins; $T G$ triglyceride; $F P G$ fasting plasma glucose; $T 2 D M$ type 2 diabetes mellitus

differences in BMI, smoking, non-T2DM prevalence, FPG and lipid profile between the two groups.

\section{Serum $O C$ forms and circulating EPC OC + in coronary atherosclerosis}

The circulating levels of OC forms (cOC, ucOC, TOC and $\mathrm{ucOC} / \mathrm{TOC}$ ) in the ECA group did not differ from those observed in the LCA group (Table 2). Regarding EPC OC + count, we observed that patients with EPC $\mathrm{OC}+$ counts above the 75 th percentile showed significant differences in circulating EPC OC + counts between groups $(p=0.02)$, with LAC subjects showing more elevated EPC OC + counts (Table 2, Fig. 1).

All patients had at least one CVRF. CVRFs number was associated with changes of unOC and TOC levels and EPC $\mathrm{OC}+$ count. A significant decrease of unOC levels was observed in parallel with the increase of number of CVRFs $(p=0.02)$ (Fig. 2A). A similar trend was also observed for TOC $(p=0.04)$ (Fig. 2B). On the contrary, a significant increase of EPC OC + count was observed with the increase of CVRFs number ( $p=0.04)$ (Fig. 3). 
Table 2 Circulating levels of osteocalcin forms and EPCs OC + count according to study groups

\begin{tabular}{llll}
\hline & ECA $(n=22)$ & LCA $(n=37)$ & $p$ value \\
\hline EPC OC+* (cells/mL) & $359(247-517)$ & $1673(251-2513)$ & $\mathbf{0 . 0 2 * *}$ \\
cOC $(\mathrm{ng} / \mathrm{mL})$ & $7.35 \pm 3.25$ & $6.83 \pm 2.85$ & 0.60 \\
$\mathrm{ucOC}(\mathrm{ng} / \mathrm{mL})$ & $2.09 \pm 1.74$ & $2.57 \pm 1.86$ & 0.27 \\
$\mathrm{ucOC} / \mathrm{TOC}$ & $0.23 \pm 0.12$ & $0.29 \pm 0.21$ & 0.55 \\
TOC $(\mathrm{ng} / \mathrm{mL})$ & $9.44 \pm 5.25$ & $9.87 \pm 6.72$ & 0.99 \\
\hline
\end{tabular}

Data are expressed as mean \pm standard deviation or median and interquartile range

Significant $p$ values are in bold. *defined as $>75$ th percentile, ** $t$-test

$E C A$ early cardiovascular atherosclerosis; $L C A$ late cardiovascular atherosclerosis; EPC $O C+$ endothelial progenitor cells expressing osteocalcin; $c O C$ carboxylated osteocalcin; $u c O C$ undercarboxylated osteocalcin; TOC total osteocalcin

\section{Correlation analysis of EPC OC + count with clinical parameters and levels of OC forms}

In the whole study population, EPC OC + count was positively correlated with TC, LDL-C and TG, but not with other demographic and clinical parameters related to CVD risk (Table 3). In the LCA group, but not in the ECA group, the correlation of EPC OC + count with TC, LDL-C and TG was also present (Table 3). The correlation analysis between EPC $\mathrm{OC}+$ count and different $\mathrm{OC}$ forms is reported in Table 4. In the whole study population, EPC OC + count was inversely correlated with unOC levels and unOC/TOC (both $p<0.01$ ).
This correlation was also present in the LCA group for both unOC and unOC/TOC $(p<0.01)$.

\section{Discussion}

It has recently been hypothesized that EPC OC + are involved in the mechanism of calcification by promoting abnormal vascular repair [19]. Moreover, circulating EPC $\mathrm{OC}+$ found in the peripheral blood have been shown to be able to activate calcification in vitro and in vivo [29]. Based on these assumptions, this study was designed to evaluate, for the first time to the best of our knowledge, all different forms of OC as well as EPCs expressing OC + counts in the context of patients with coronary atherosclerosis. Our study showed significant differences in circulating EPC $\mathrm{OC}+$ counts between LAC and ECA groups, with EPC $\mathrm{OC}+$ count increased with the severity of CAD, possibly suggesting an active role for EPC OC + in the development of atherosclerosis. This is consistent with several studies [28-33] demonstrating a significant positive correlation between OC-positive cells and increased vascular calcification or atherosclerosis.

In our study, an inverse correlation between ucOC, ucOC/ TOC and EPC OC + in CAD was found. This indicates a potentially protective role for ucOC that is consistent with previous studies [34, 35], showing that circulating ucOC is, for example, inversely correlated with insulin resistance.

In the current study, we observed a new relationship between EPC OC + and lipid indexes, since EPC
Fig. 1 EPC OC + counts (median and range) in ECA and LCA groups, referred to patients above the 75th percentile of $\mathrm{EPC} \mathrm{OC}+$ count (ECA: early cardiovascular atherosclerosis. LCA: late cardiovascular atherosclerosis. EPC OC + : endothelial progenitor cells expressing osteocalcin)

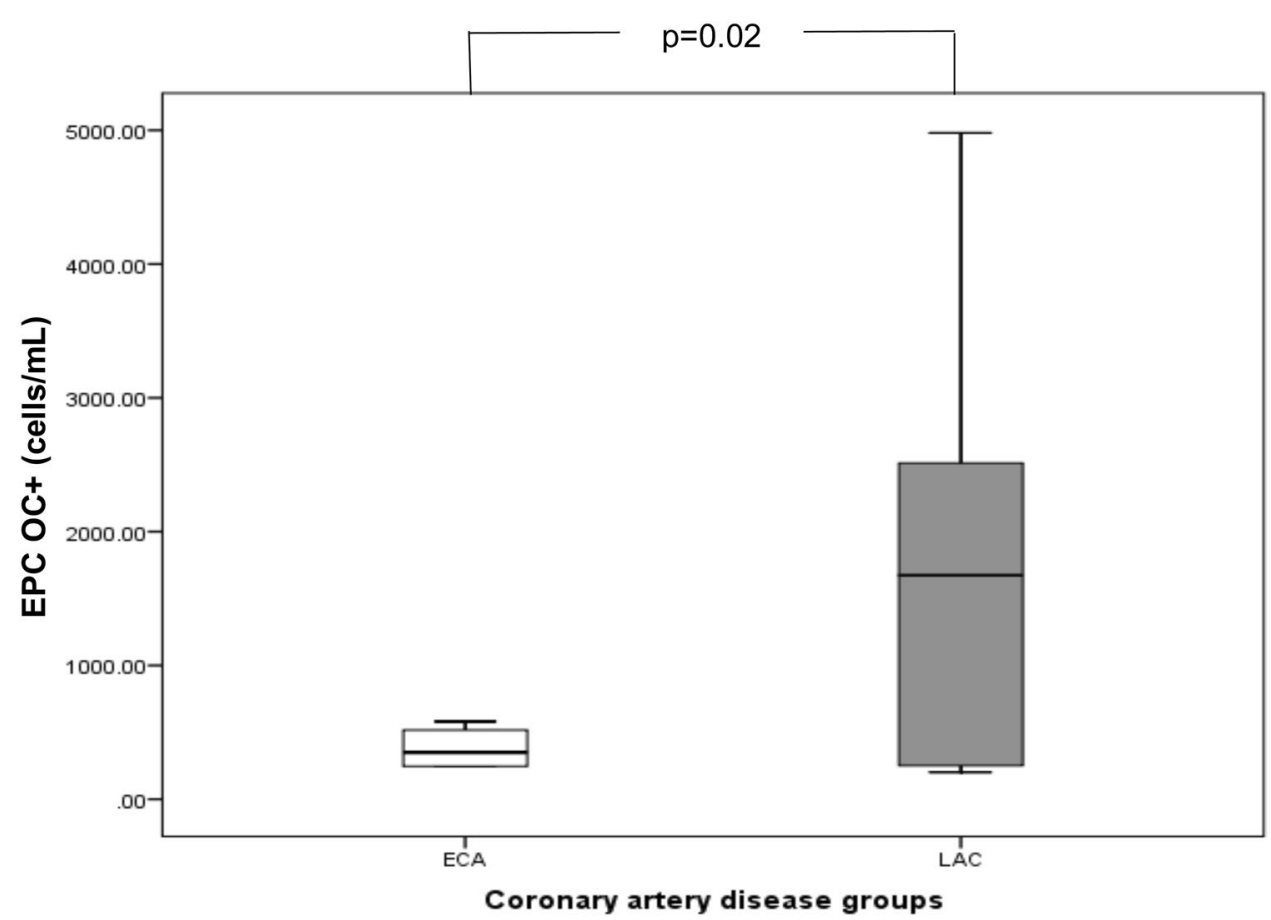


Fig. 2 Relationship of A undercarboxylated osteocalcin (unOC) and $\mathbf{B}$ total osteocalcin (TOC) levels with the number of cardiovascular risk factors (CVRFs). unOC and TOC are expressed as mean $\pm \mathrm{SD}$. unOC and TOC levels significantly decreased in relationship with increasing number of CVRFs $(p=0.02$ and $p=0.04$, respectively; Kruskal-Wallis test)

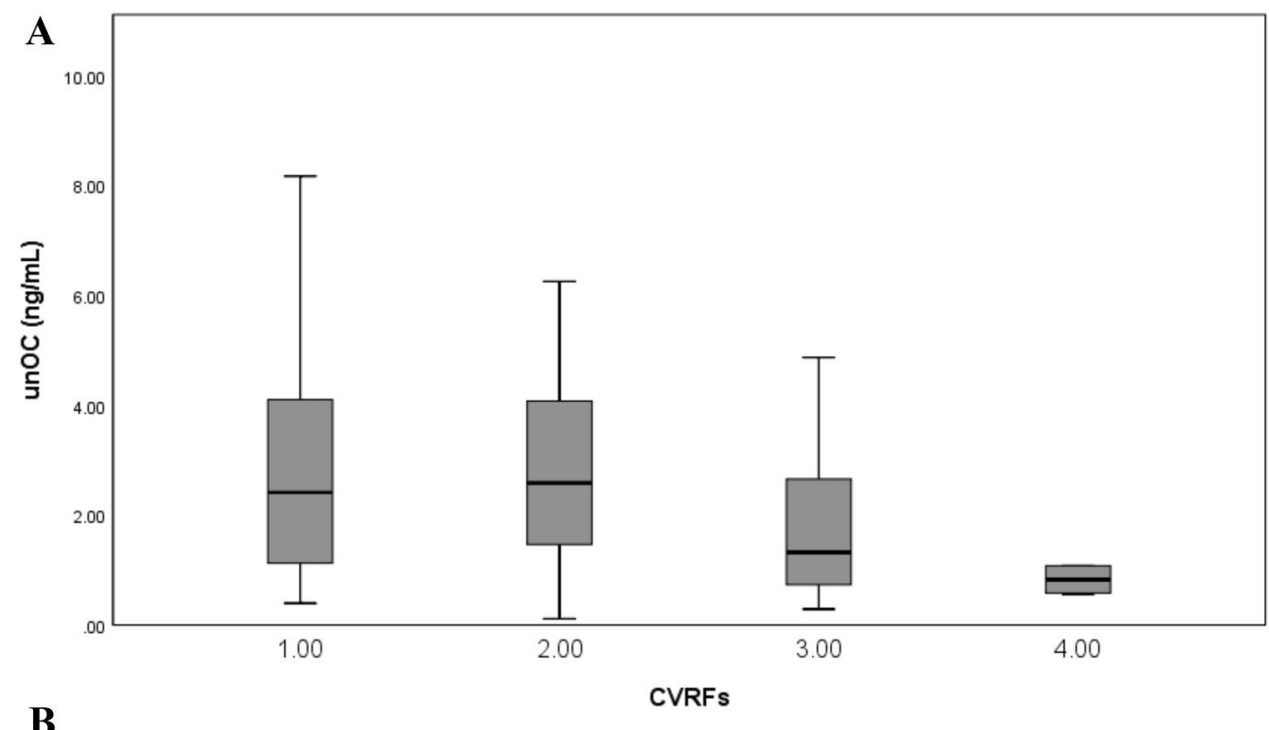

B

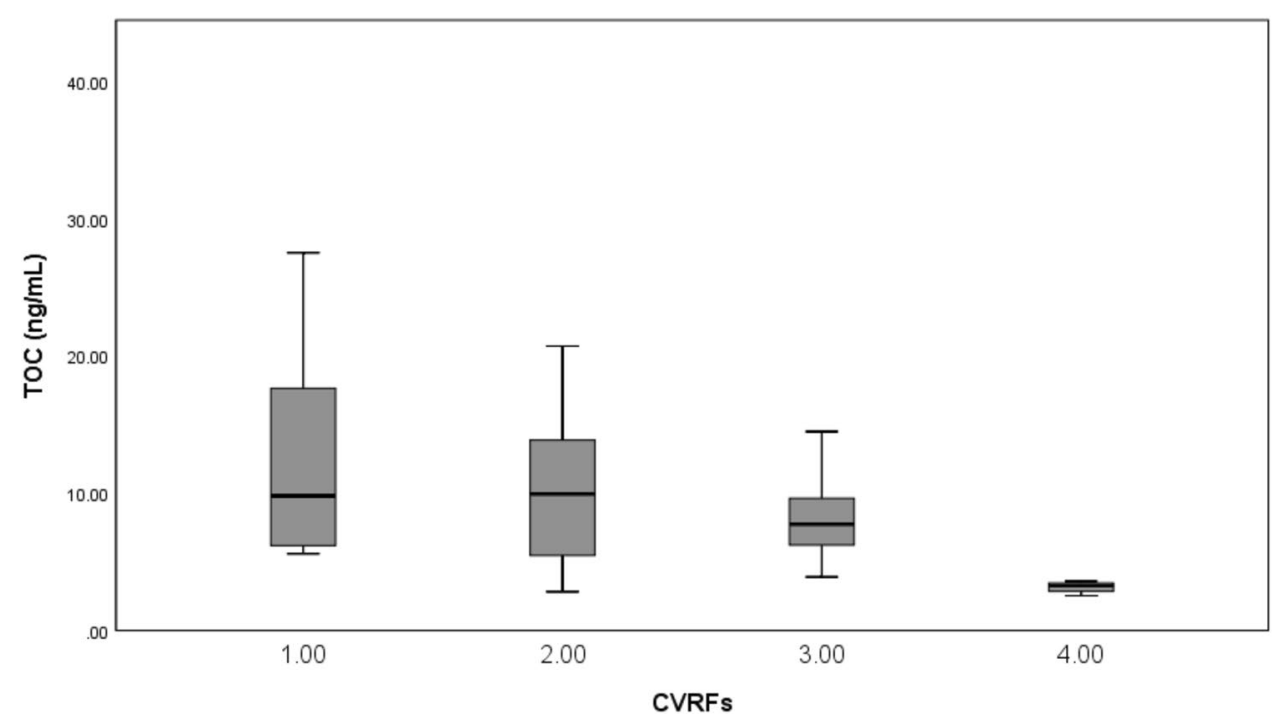

$\mathrm{OC}+$ positively correlated with TC, LDL-C, and TG, suggesting that EPC OC + count may play a role in the evaluation of the $\mathrm{CV}$ risk in patients with $\mathrm{CAD}$. In a populationbased study, EPC counts were positively correlated with CVRFs [36], and Ivaska et al. demonstrated an inverse correlation of these cells with CVRFs [37]. However, recent research has provided conflicting results [29].

There is little evidence describing the relationship between serum levels of ucOC, EPC OC + counts, and CVRFs [20]. In our study, we found TOC and ucOC to be similarly inversely correlated with increasing number of CVRFs. This suggests that OC, but not its carboxylation status, may be relevant to improve the metabolic profile and to reduce $\mathrm{CV}$ risk. This finding is supported by metaanalyses reporting that TOC and unOC are similarly and negatively correlated with FPG, and glycated hemoglobin
(HbA1c) in humans [11]. We found that EPC OC + counts correlated with increasing number of CVRFs, a finding that supports the active role of $\mathrm{EPC} \mathrm{OC}+$ in developing atherosclerosis.

We found no association between various forms of circulating OC (total, ucOC, or cOC) and severity of CAD, possibly due to the small sample size, which in this case represent a limitation of the study. A limitation of this study, intrinsic to the fact that it has been conducted in humans, is that the highlighted relationships could not be further explored in their possible causal association. This may be the object of future translational experiments. Next studies will also address the potential sex differences of such vascular calcification process, in the context of the well-known peculiarities in ASCVD risk and treatment [38]. In addition, since proprotein convertase subtilisin kexin type 9 , in 
Fig. 3 EPC OC + counts in relation to the number of cardiovascular risk factors (CVRFs). A significant increase in EPC $\mathrm{OC}+$ counts were observed with a higher number of CVRFs $(p=0.04$, Kruskal-Wallis test). Data are expressed as mean $\pm \mathrm{SD}$

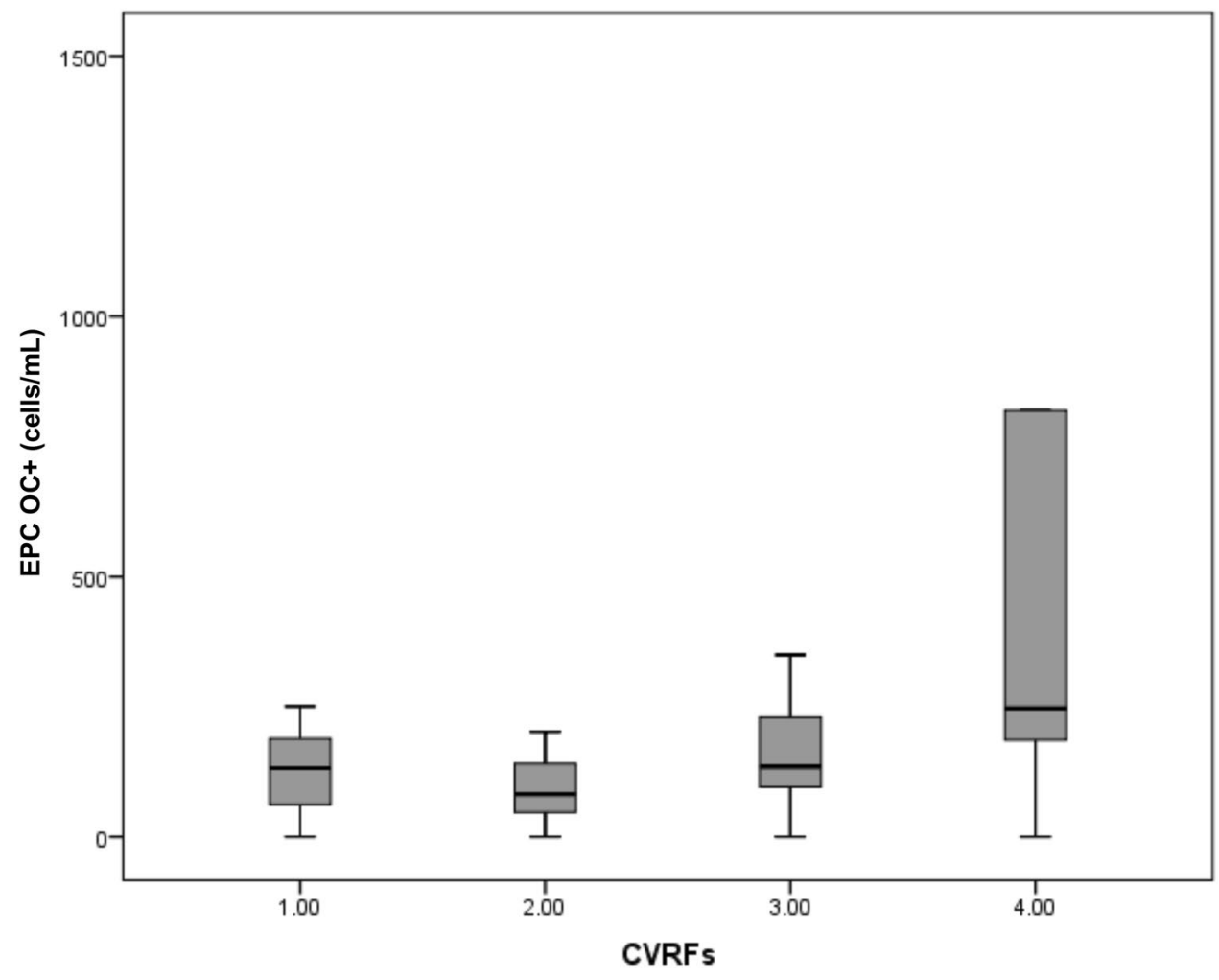

Table 3 Correlation between EPC OC + and individual cardiovascular risk factors

\begin{tabular}{lclc}
\hline & \multicolumn{2}{l}{ EPC OC +} \\
\cline { 2 - 4 } & $\begin{array}{l}\text { Whole cohort } \\
(n=59)\end{array}$ & ECA $(n=22)$ & LCA $(n=37)$ \\
\hline Age & 0.005 & -0.166 & 0.021 \\
BMI & 0.001 & 0.043 & 0.000 \\
Smoking & 0.139 & 0.147 & 0.117 \\
CVRFs & 0.191 & 0.185 & 0.183 \\
Gender & -0.083 & 0.101 & -0.160 \\
TC & $0.459^{* *}$ & 0.202 & $0.611^{* *}$ \\
HDL-C & 0.120 & 0.213 & 0.069 \\
LDL-C & $0.408^{* *}$ & -0.080 & $0.621^{* *}$ \\
TG & $0.346^{* *}$ & 0.339 & $0.373^{*}$ \\
FPG & 0.025 & -0.281 & 0.263 \\
\hline
\end{tabular}

$* p<0.05 ; * *<<0.01$ (Spearman correlation coefficients)

EPC $O C+$ endothelial progenitor cells expressing osteocalcin; ECA early cardiovascular atherosclerosis; $L C A$ late cardiovascular atherosclerosis; $B M I$ body mass index; $C V R F s$ cardiovascular risk factors; $T C$ total cholesterol; $H D L-C$ cholesterol bound to high density lipoproteins; $L D L-C$ cholesterol bound to low-density lipoproteins; $T G$ triglyceride; $F P G$ fasting plasma glucose

addition to control LDL-C levels [39], has been shown to contribute to vascular and valvular calcification [40], it will be interesting to further unveil its potential relationship with $\mathrm{EPC} \mathrm{OC+}$ and $\mathrm{OC}$.
Table 4 Correlation between EPC OC + and different forms of osteocalcin

\begin{tabular}{llcl}
\hline \multirow{4}{*}{} & \multicolumn{3}{l}{ EPC OC +} \\
\cline { 2 - 4 } & Whole cohort $(n=59)$ & ECA $(n=22)$ & LCA $(n=37)$ \\
\hline cOC & 0.138 & 0.246 & 0.036 \\
ucOC & $-0.390^{* *}$ & -0.199 & $-0.505^{* *}$ \\
ucOC/TOC & $-0.426^{* *}$ & -0.312 & $-0.470^{* *}$ \\
TOC & -0.004 & 0.142 & -0.088 \\
\hline
\end{tabular}

$*^{*} p<0.01$ (Spearman correlation coefficients)

$E P C O C+$ endothelial progenitor cells expressing osteocalcin; $E C A$ early cardiovascular atherosclerosis; $L C A$ late cardiovascular atherosclerosis; $c O C$ carboxylated osteocalcin; $u c O C$ undercarboxylated osteocalcin; TOC total osteocalcin

\section{Conclusions}

The present study measured the three independent forms of circulating $\mathrm{OC}$ and $\mathrm{EPC} \mathrm{OC}+$ count in CAD patients. We found a significant association between circulating early EPCs (CD34-CD133 + KDR + OC +), CAD severity, and CVRFs. This suggests an active role for EPC OC + in developing atherosclerosis. We showed a novel inverse correlation between ucOC and $\mathrm{EPC} \mathrm{OC}+$ in CAD, indicating a protecting role for unOC. We also found an inverse correlation between TOC and ucOC and number of CVRFs, suggesting 
that OC, but not its carboxylation status, may be developed as a further cardiovascular risk biomarker. These findings have potential implications for the mechanisms of vascular calcification and for the development of novel markers to identify patient at low or high coronary atherosclerosis risk and suggest a novel link between bone metabolism and progression of coronary atherosclerosis.

Supplementary Information The online version contains supplementary material available at https://doi.org/10.1007/s40618-022-01744-3.

\section{Acknowledgements None.}

Author contributions HES contributed to the conception and design of the work, analyzed the data, contributed to the interpretation of the data and wrote the manuscript; SAF contributed to the interpretation of the data and critically revised the manuscript; GA contributed to the acquisition of the data and critically revised the manuscript; ARA contributed to the conception and design of the work, acquisition and interpretation of the data and critically revised the manuscript; PM contributed to the design of the work, acquisition and interpretation of the data and critically revised the manuscript. All authors approved the final version of the manuscript for publication and they are in agreement to be accountable for all aspects of the work. HES is the guarantor of this work, and as such, had full access to all the data in the study and takes responsibility for the integrity of the data and the accuracy of the data analysis.

Funding This research was supported by the Scientific Research and Technical Development Support Fund for Higher Education of the Syrian Ministry of Higher Education.

\section{Declarations}

Conflict of interest The authors have no conflicts of interest to declare.

Research involving human participants and/or animals This study was conducted with full Compliance with Ethical Standards for research involving human participants.

Informed consent All of them signed an Informed Consent.

Open Access This article is licensed under a Creative Commons Attribution 4.0 International License, which permits use, sharing, adaptation, distribution and reproduction in any medium or format, as long as you give appropriate credit to the original author(s) and the source, provide a link to the Creative Commons licence, and indicate if changes were made. The images or other third party material in this article are included in the article's Creative Commons licence, unless indicated otherwise in a credit line to the material. If material is not included in the article's Creative Commons licence and your intended use is not permitted by statutory regulation or exceeds the permitted use, you will need to obtain permission directly from the copyright holder. To view a copy of this licence, visit http://creativecommons.org/licenses/by/4.0/.

\section{References}

1. Wang TJ (2011) Assessing the role of circulating, genetic, and imaging biomarkers in cardiovascular risk prediction. Circulation
123(5):551-565. https://doi.org/10.1161/CIRCULATIONAHA. 109.912568

2. Vasan RS (2006) Biomarkers of cardiovascular disease: molecular basis and practical considerations. Circulation 113(19):23352362. https://doi.org/10.1161/CIRCULATIONAHA.104.482570

3. Baragetti A, Catapano AL, Magni P (2020) Multifactorial activation of NLRP3 inflammasome: relevance for a precision approach to atherosclerotic cardiovascular risk and disease. Int J Mol Sci 21(12):4459. https://doi.org/10.3390/ijms21124459

4. Johnson RC, Leopold JA, Loscalzo J (2006) Vascular calcification: pathobiological mechanisms and clinical implications. Circ Res 99(10):1044-1059. https://doi.org/10.1161/01.RES.00002 49379.55535.21

5. Kosmopoulos M, Paschou SA, Grapsa J, Anagnostis P, Vryonidou A, Goulis DG et al (2019) The emerging role of bone markers in diagnosis and risk stratification of patients with coronary artery disease. Angiology 70(8):690-700. https://doi.org/10. $1177 / 0003319718822625$

6. Lee NK, Sowa H, Hinoi E, Ferron M, Ahn JD, Confavreux C et al (2007) Endocrine regulation of energy metabolism by the skeleton. Cell 130(3):456-469. https://doi.org/10.1016/j.cell. 2007.05.047

7. Riddle RC, Clemens TL (2017) Bone cell bioenergetics and skeletal energy homeostasis. Physiol Rev 97(2):667-698. https://doi.org/10.1152/physrev.00022.2016

8. Liu JM, Rosen CJ, Ducy P, Kousteni S, Karsenty G (2016) Regulation of glucose handling by the skeleton: insights from mouse and human studies. Diabetes 65(11):3225-3232. https:// doi.org/10.2337/db16-0053

9. Magni P, Dozio E, Galliera E, Ruscica M, Corsi MM (2010) Molecular aspects of adipokine-bone interactions. Curr Mol Med 10(6):522-532. https://doi.org/10.2174/156652401100906 0522

10. Ferron M, McKee MD, Levine RL, Ducy P, Karsenty G (2012) Intermittent injections of osteocalcin improve glucose metabolism and prevent type 2 diabetes in mice. Bone 50(2):568-575. https:// doi.org/10.1016/j.bone.2011.04.017

11. Liu DM, Guo XZ, Tong HJ, Tao B, Sun LH, Zhao HY et al (2015) Association between osteocalcin and glucose metabolism: a metaanalysis. Osteoporos Int 26(12):2823-2833. https://doi.org/10. 1007/s00198-015-3197-8

12. Ducy $P$ (2011) The role of osteocalcin in the endocrine cross-talk between bone remodelling and energy metabolism. Diabetologia 54(6):1291-1297. https://doi.org/10.1007/s00125-011-2155-Z

13. Zoch ML, Clemens TL, Riddle RC (2016) New insights into the biology of osteocalcin. Bone 82:42-49. https://doi.org/10.1016/j. bone.2015.05.046

14. Hauschka PV, Lian JB, Cole DE, Gundberg CM (1989) Osteocalcin and matrix Gla protein: vitamin K-dependent proteins in bone. Physiol Rev 69(3):990-1047. https://doi.org/10.1152/physr ev.1989.69.3.990

15. Gundberg CM, Nieman SD, Abrams S, Rosen H (1998) Vitamin $\mathrm{K}$ status and bone health: an analysis of methods for determination of undercarboxylated osteocalcin. J Clin Endocrinol Metab 83(9):3258-3266. https://doi.org/10.1210/jcem.83.9.5126

16. Shao J, Wang Z, Yang T, Ying H, Zhang Y, Liu S (2015) Bone regulates glucose metabolism as an endocrine organ through osteocalcin. Int J Endocrinol 2015:967673. https://doi.org/10.1155/ 2015/967673

17. Zhou C, Niu Y, Xu H, Li Z, Wang T, Yang W et al (2018) Mutation profiles and clinical characteristics of Chinese males with isolated hypogonadotropic hypogonadism. Fertil Steril 110(3):48695.e5. https://doi.org/10.1016/j.fertnstert.2018.04.010

18. Karsenty G, Oury F (2014) Regulation of male fertility by the bone-derived hormone osteocalcin. Mol Cell Endocrinol 382(1):521-526. https://doi.org/10.1016/j.mce.2013.10.008 
19. Millar SA, Patel H, Anderson SI, England TJ, O'Sullivan SE (2017) Osteocalcin, vascular calcification, and atherosclerosis: a systematic review and meta-analysis. Front Endocrinol (Lausanne) 8:183. https://doi.org/10.3389/fendo.2017.00183

20. Sanchez-Enriquez S, Ballesteros-Gonzalez IT, Villafán-Bernal JR, Pascoe-Gonzalez S, Rivera-Leon EA, Bastidas-Ramirez BE et al (2017) Serum levels of undercarboxylated osteocalcin are related to cardiovascular risk factors in patients with type 2 diabetes mellitus and healthy subjects. World J Diabetes 8(1):11-17. https:// doi.org/10.4239/wjd.v8.i1.11

21. Magni P, Macchi C, Sirtori CR, Corsi Romanelli MM (2016) Osteocalcin as a potential risk biomarker for cardiovascular and metabolic diseases. Clin Chem Lab Med 54(10):1579-1587. https://doi.org/10.1515/cclm-2015-0953

22. Zhang M, Ni Z, Zhou W, Qian J (2015) Undercarboxylated osteocalcin as a biomarker of subclinical atherosclerosis in non-dialysis patients with chronic kidney disease. J Biomed Sci 22:75. https:// doi.org/10.1186/s12929-015-0183-6

23. Razzaque MS (2011) Osteocalcin: a pivotal mediator or an innocent bystander in energy metabolism? Nephrol Dial Transplant 26(1):42-45. https://doi.org/10.1093/ndt/gfq721

24. Tacey A, Hayes A, Zulli A, Levinger I (2021) Osteocalcin and vascular function: is there a cross-talk? Mol Metab 49:101205. https://doi.org/10.1016/j.molmet.2021.101205

25. Tacey A, Millar S, Qaradakhi T, Smith C, Hayes A, Anderson S et al (2021) Undercarboxylated osteocalcin has no adverse effect on endothelial function in rabbit aorta or human vascular cells. $\mathrm{J}$ Cell Physiol 236(4):2840-2849. https://doi.org/10.1002/jcp.30048

26. Adams V, Lenk K, Linke A, Lenz D, Erbs S, Sandri M et al (2004) Increase of circulating endothelial progenitor cells in patients with coronary artery disease after exercise-induced ischemia. Arterioscler Thromb Vasc Biol 24(4):684-690. https://doi.org/10.1161/ 01.ATV.0000124104.23702.a0

27. Urbich C, Dimmeler S (2004) Endothelial progenitor cells: characterization and role in vascular biology. Circ Res 95(4):343-353. https://doi.org/10.1161/01.RES.0000137877.89448.78

28. Gössl M, Mödder UI, Atkinson EJ, Lerman A, Khosla S (2008) Osteocalcin expression by circulating endothelial progenitor cells in patients with coronary atherosclerosis. J Am Coll Cardiol 52(16):1314-1325. https://doi.org/10.1016/j.jacc.2008.07.019

29. Flammer AJ, Gössl M, Widmer RJ, Reriani M, Lennon R, Loeffler D et al (2012) Osteocalcin positive CD133+/CD34-/KDR+ progenitor cells as an independent marker for unstable atherosclerosis. Eur Heart J 33(23):2963-2969. https://doi.org/10.1093/ eurheartj/ehs234

30. Yang SW, Hennessy RR, Khosla S, Lennon R, Loeffler D, Sun $\mathrm{T}$ et al (2017) Circulating osteogenic endothelial progenitor cell counts: new biomarker for the severity of coronary artery disease. Int J Cardiol 227:833-839. https://doi.org/10.1016/j.ijcard.2016. 10.036

31. Pal SN, Rush C, Parr A, Van Campenhout A, Golledge J (2010) Osteocalcin positive mononuclear cells are associated with the severity of aortic calcification. Atherosclerosis 210(1):88-93. https://doi.org/10.1016/j.atherosclerosis.2009.11.001

32. Pirro M, Schillaci G, Mannarino MR, Scarponi AM, Manfredelli MR, Callarelli L et al (2011) Circulating immature osteoprogenitor cells and arterial stiffening in postmenopausal osteoporosis. Nutr Metab Cardiovasc Dis 21(9):636-642. https://doi.org/10. 1016/j.numecd.2010.01.015

33. Gössl M, Mödder UI, Gulati R, Rihal CS, Prasad A, Loeffler D et al (2010) Coronary endothelial dysfunction in humans is associated with coronary retention of osteogenic endothelial progenitor cells. Eur Heart J 31(23):2909-2914. https://doi.org/10.1093/ eurheartj/ehq373

34. Pollock NK, Bernard PJ, Gower BA, Gundberg CM, Wenger K, Misra S et al (2011) Lower uncarboxylated osteocalcin concentrations in children with prediabetes is associated with beta-cell function. J Clin Endocrinol Metab 96(7):E1092-E1099. https:// doi.org/10.1210/jc.2010-2731

35. Prats-Puig A, Mas-Parareda M, Riera-Pérez E, González-Forcadell D, Mier C, Mallol-Guisset M et al (2010) Carboxylation of osteocalcin affects its association with metabolic parameters in healthy children. Diabetes Care 33(3):661-663. https://doi.org/10. 2337/dc09-1837

36. Xiao Q, Kiechl S, Patel S, Oberhollenzer F, Weger S, Mayr A et al (2007) Endothelial progenitor cells, cardiovascular risk factors, cytokine levels and atherosclerosis-results from a large population-based study. PLoS ONE 2(10):e975. https://doi.org/10.1371/ journal.pone.0000975

37. Ivaska KK, Hentunen TA, Vääräniemi J, Ylipahkala H, Pettersson K, Väänänen HK (2004) Release of intact and fragmented osteocalcin molecules from bone matrix during bone resorption in vitro. J Biol Chem 279(18):18361-18369. https://doi.org/10. 1074/jbc.M314324200

38. Mombelli G, Bosisio R, Calabresi L, Magni P, Pavanello C, Pazzucconi $F$ et al (2015) Gender-related lipid and/or lipoprotein responses to statins in subjects in primary and secondary prevention. J Clin lipidol 9(2):226-233. https://doi.org/10.1016/j.jacl. 2014.12.003

39. Ruscica M, Ferri N, Fogacci F, Rosticci M, Botta M, Marchiano $S$ et al (2017) Circulating levels of proprotein convertase subtilisin/kexin type 9 and arterial stiffness in a large population sample: data from the Brisighella Heart Study. J Am Heart Assoc 6(5):e005764. https://doi.org/10.1161/JAHA.117.005764

40. Perrot N, Valerio V, Moschetta D, Boekholdt SM, Dina C, Chen HY et al (2020) Genetic and in vitro inhibition of PCSK9 and calcific aortic valve stenosis. JACC Basic Transl Sci 5(7):649-661. https://doi.org/10.1016/j.jacbts.2020.05.004

Publisher's Note Springer Nature remains neutral with regard to jurisdictional claims in published maps and institutional affiliations. 